\title{
Evaluation of Soap Produced from Agricultural Wastes and Non- Edible Oil as a Substitute for Conventional Surfactants used in Enhanced Oil Recovery
}

\author{
Azuokwu Augustine Azubike*, Obeta Perpetual Oby, Adedigba Oluwatimileyin Victor, Akeke \\ Jumokumoh Johnson \\ ${ }^{I}$ Chemical \& Petroleum Engineering Department, Igbinedion University, Okada. Edo State, Nigeria
}

*Corresponding Author: Azuokwu Augustine Azubike, Chemical \& Petroleum Engineering Department, Igbinedion University, Okada. Edo State, Nigeria.

\begin{abstract}
Based on the cost of the conventional surfactants used in enhanced oil recovery coupled with decrease in global hydrocarbons prices as well as the desire to contribute to local content initiative, this study was carried out to determine the suitability of using soap produced from agricultural wastes and nonedible seed oils as substitutes for the conventional surfactants.

The soap was produced using non edible plant seed oil extracted from Jatropha curcas seeds and alkali produced using the plantain (Musa Paradisiaca) peels ash. Laboratory experiments (interfacial tension measurements and flooding experiments) were conducted to compare the performance of the produced soap and two conventional surfactants (Sodium Dodecyl Sulfate and Tween 80).

The interfacial tension (IFT) values obtained showed that the produced soap reduced the interfacial tension as much as the conventional surfactants. Increased in concentrations or temperature of the surfactants reduced the interfacial tensions further more.

The displacement efficiencies and recovery factors results from the flooding experiments showed that the produced soap compared favourably with the conventional surfactants. The results were higher for water wet systems than oil wet systems.

The interfacial tension measurements and flooding results further showed that soap (the earliest surfactants known to man) could be used as a substitute for conventional surfactants used in enhanced oil recovery.
\end{abstract}

Keywords: Conventional Surfactants, Enhanced Oil Recovery, Soap, Agricultural Wastes, Non-edible Plant Seed Oil, Interfacial Tension Measurements, Flooding Experiments

\section{INTRODUCTION}

The recovery of oil from the reservoir usually undergoes several phases. These phases are termed primary oil recovery, secondary oil recovery, and tertiary (enhanced) oil recovery (Tarek, 2010 Nwidee et al., 2016; Abdelmalek and Kamal 2018).

During the primary recovery phase, the natural reservoir energy stored as pressure in the reservoir fluids and the underlying aquifer is used to drive the hydrocarbon through the pore network to the production wells. The primary energy comes from the natural drive of the reservoir such as depletion, gas cap, gravity drainage, water, rock compaction and a combination drive. In most cases, the natural driving mechanism is a relatively inefficient process and results in a low overall oil recovery.

Secondary oil recovery refers to the additional recoveries that result by supplementing the the natural energy of a petroleum reservoir by the injection of fluids, normally water or gas.

A considerable portion (roughly 65\%) of the total oil in place (OIP) present in mature reservoirs cannot be extracted by primary and secondary recovery mechanisms (Morrow, 1991, Taber et al, 1997 and Saleem, 2011).

The methods that are used to recover oil beyond the conventional methods (primary and secondary recovery mechanisms) are called enhanced oil recovery (EOR) or tertiary oil recovery processes. These are further classified under four main groups: miscible gas injection processes, chemical processes, microbial and thermal processes (Sunil and Al-Kaabi, 2009). 
Evaluation of Soap Produced from Agricultural Wastes and Non-Edible Oil as a Substitute for Conventional Surfactants used in Enhanced Oil Recovery

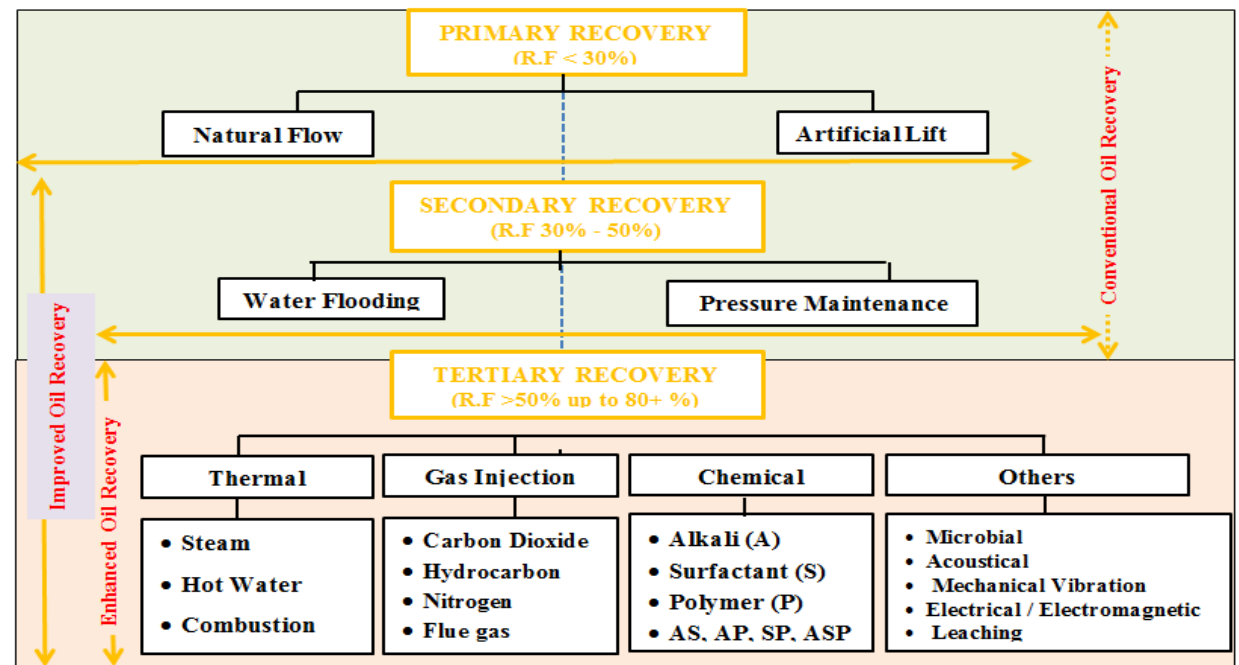

Figure1. Oil Recovery Mechanisms (Adapted from: Islin and Maxim, 2013).

Chemical methods for enhanced oil recovery (EOR) consist of the injection of a displacing fluid such as surfactants, polymers, alkalis etc. in oil reservoirs to mobilize the crude oil trapped in the porous rocks.

Surfactants are compounds that lower the surface tension (or interfacial tension) between two liquids, between a gas and a liquid, or between a liquid and a solid. Surfactants may act as detergents, wetting agents, emulsifiers, foaming agents or dispersants (Salager, 2002). The earliest surfactants known to man are soaps (ECI, 2013).

Surfactants are usually organic compounds that are amphiphilic, meaning they contain both hydrophobic groups (their tails- lipophilic) and hydrophilic groups (their heads- lipophobic) (Porte, 1994). The hydrophilic group is soluble in water and insoluble in oil. The other part is called the lipophilic group which is soluble in oil but is not soluble in water. Two kinds of groups are in the opposite directions, and both ends are connected to bond in the same molecule, forming an asymmetric and polar structure. Surfactants classified as Non-ionic, Anionic; Cationic and Zwitterionic (Salager, 2002; Susanna, 2018).

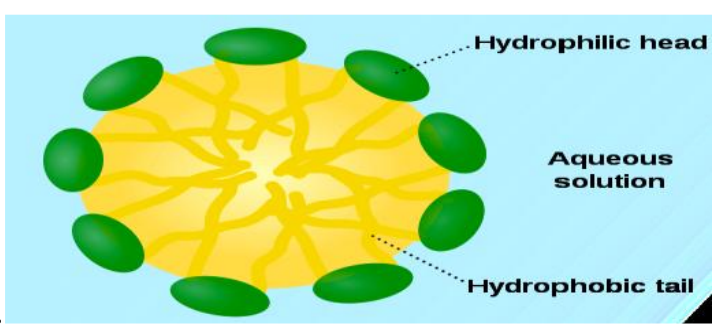

Figure2. The structure of the surfactant (LTS, 2011).

Table1. Types of surfactant (Adapted from: LTS, 2011; Susanna, 2018; Afeez et al., 2019).

\begin{tabular}{|c|c|c|}
\hline Surfactant Types & Legend: (Hydrophil; Hydrophob) & Structure \\
\hline 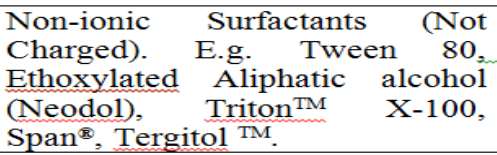 & & $\mathrm{R}-\mathrm{O}-\mathrm{CH}_{2}-\underset{\mathrm{CH}_{2}-\mathrm{CH}}{\mathrm{CH}}=\mathrm{CH}_{3}$ \\
\hline $\begin{array}{l}\text { Anionic Surfactants (Negatively } \\
\text { Charged) E.g. Soaps, Sodium } \\
\text { dodecyl sulphate (SDS), Teepol, } \\
\text { Texapon }{ }^{\circledR} \text {, Calsoft }\end{array}$ & & \\
\hline $\begin{array}{l}\text { Cationic Surfactants (Positively } \\
\text { Charged) E.g. Cetyl trimethyl } \\
\text { ammonium bromide (CTAB), } \\
\text { ARQUAD } \\
\text { T-50 }\end{array}$ & & I \\
\hline $\begin{array}{lrr}\text { Amphoteric } & \text { (Zwitterionic) } \\
\text { Surfactants } & \text { (Positively \& } \\
\text { Negatively } & \text { Charged) } & \text { E.g. } \\
\text { Dodecyl betaine, Amphoacetates }\end{array}$ & & $\mathrm{CH}_{3}$ \\
\hline
\end{tabular}


Surfactants are commonly used in EOR processes for various purposes, including oil/water interfacial tension reduction, wettability alteration, and foam generation (Jerauld and Rathmell, 1997; Hirasaki et al. 2008; Udeagbara, 2010; Farid, 2012; Alvarez J.O. and Schechter 2017). Surfactant flooding has been adjudged an encouraging enhanced oil recovery method (Olajire, 2014, Demirbas et al, 2015). They are increasingly being used as enhanced oil recovery method in matured / brown fields in oil and gas industries (Gary, 2007; Sandersen, 2012; Demirbas et al, 2015). However, surfactants are also some of the most expensive chemicals used during EOR (Negin el al., 2016). The cost of the conventional surfactants used in enhanced oil recovery coupled with decrease in global hydrocarbons prices have led to the search for low cost surfactants that can be used in place of conventional ones (William et al., 2007; Iglauer et al., 2009; Bikkina et al., 2013; Mohammad et al., 2014: Adeniyi et al., 2015; Funsho 2015; Hamza et al., 2017; Ojo and Fadairo, 2017; Afeez et al., 2019). The purpose of this study was to therefore to determine the suitability of using soaps (surfactants) produced from agricultural wastes and non-edible seed oils as substitutes for conventional surfactants in enhanced oil recovery. This study is imperative now that the Nigerian oil reservoirs nearing maturity and also bearing in mind that the use of locally produced surfactants can drastically reduce the enhanced oil recovery cost as well as improve the economy of Nigeria through the local content initiative (LCI) and waste to wealth concept.

\section{Materials AND Methods}

The work flows were as follows:

(a) Production of soap produced from agricultural wastes and non-edible oil.

- Extraction of the oils from non-edible plant seeds (Jatropha seeds) and tests.

- Preparation of alkali for soap production using locally sourced plantain peels.

- Soap Production

- Soap properties Tests

(b) Performance evaluation of the produced soap and conventional surfactants in chemical enhanced oil recovery operations

- Sample preparations

- Measurement of the interfacial tension

- Flooding experiments (Water wet and Oil wet cases).

- Comparative analysis

\subsection{Production of Soap Produced from Agricultural Wastes and Non-Edible Oil.}

Surfactants are the main components in household detergent and soaps. Soaps were the earliest surfactants known to man and are classified as anionic surfactants. Generally, soap making is based on alkaline hydrolysis of an ester (saponification).

Fat or oil $+\mathrm{NaOH} \rightarrow$ sodium salt of a fatty acid (soap) + glycerol

Fat or oil $+\mathrm{KOH} \rightarrow$ potassium salt of a fatty acid (soap) + glycerol

\section{(A) Extraction of the oils from non-edible plant seeds (Jatropha seeds) and tests}

The Jatropha seeds were sourced from Ovia North East Local Government Area of Edo State. Solvent extraction method was used to extract the oil. The extraction procedure is given below:

a) The kernels of the Jatropha seeds were crushed and grinded to a pulp.

b) The sample was loaded into the main chamber of the Soxhlet extractor.

c) The chamber was fitted into a flask containing $300 \mathrm{ml}$ of $\mathrm{n}-\mathrm{Hexane}$.

d) The heating mantle was turned on and the system was left to heat at $70^{\circ} \mathrm{C}$. The solvent was heated to reflux. The solvent vapour travelled up a distillation arm, and flooded into the chamber 
Evaluation of Soap Produced from Agricultural Wastes and Non-Edible Oil as a Substitute for Conventional Surfactants used in Enhanced Oil Recovery

housing the solid wrapped in filter papers. The condenser condensed the solvent vapour, and the vapour dripped back down into the chamber housing the solid material.

e) Then at a certain level, the siphon emptied the liquid into the flask.

f) The extracted oil was then poured into 75 litres IUO water plastic bottle.

The Specific gravity, pH, Acid value, Free Fatty Acid, viscosity and the yield of the oil were determined in line with methods described by Akintayo, 2004; Warra, 2012; Hareesh et al, 2013; and Sulaiman et al, 2017.

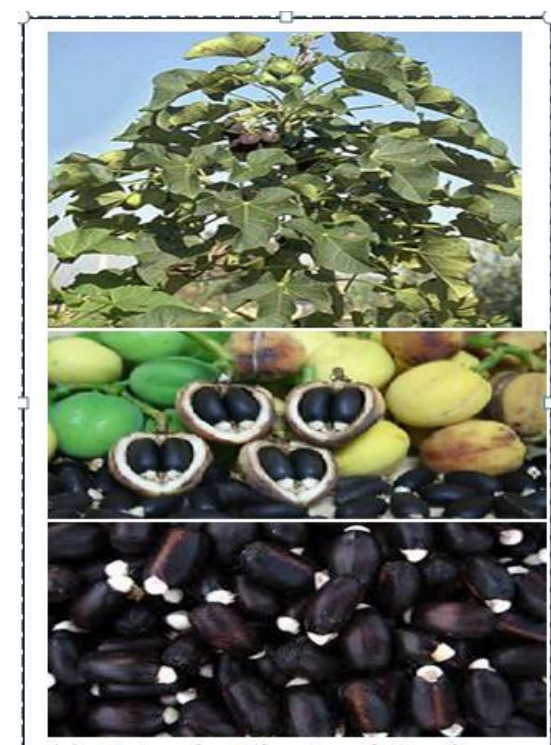

(a) Jatropha Plant and Seeds

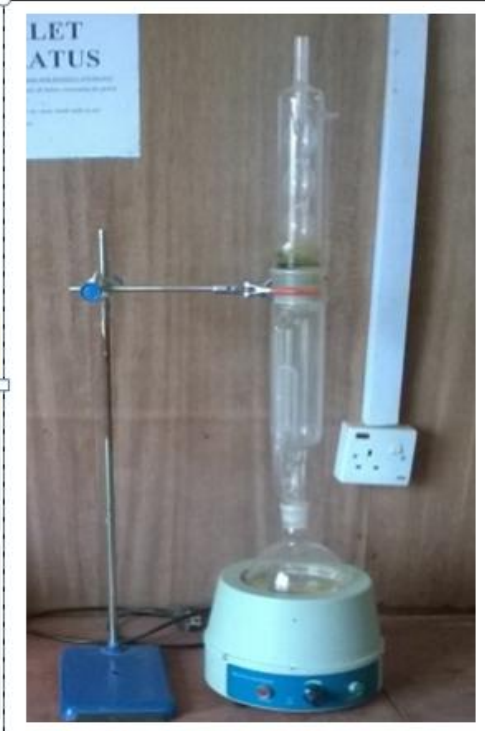

(b) Soxhlet apnaratus

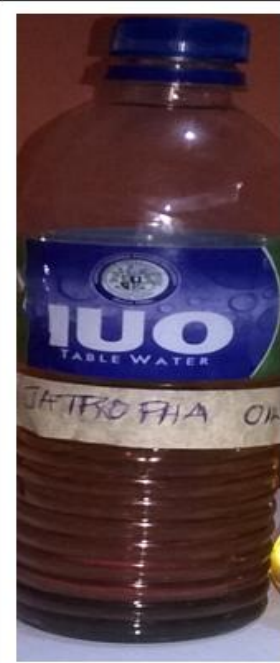

(c) Jatropha Seeds Oil

Figure3. Sourcing and extraction of oil non-edible plant seeds (Jatropha).

\section{(B) Preparation of alkali for soap production using locally sourced plantain peels}

The plantain (Musa Paradisiaca) peels were sourced from Okada town. The peels were washed and separated from sand and dirt and dry in the sun for two weeks until it is properly dried. The peels were processed into ashes as a source of alkali as shown in Figure 3.4. The plantain ash from was further heated in an electric muffle furnace at $600 \mathrm{oC}$ for 3 hours. The ash was then boiled and allowed socked in water for 24 hours. The soaked ash was then filtered. The filtrate concentrated.

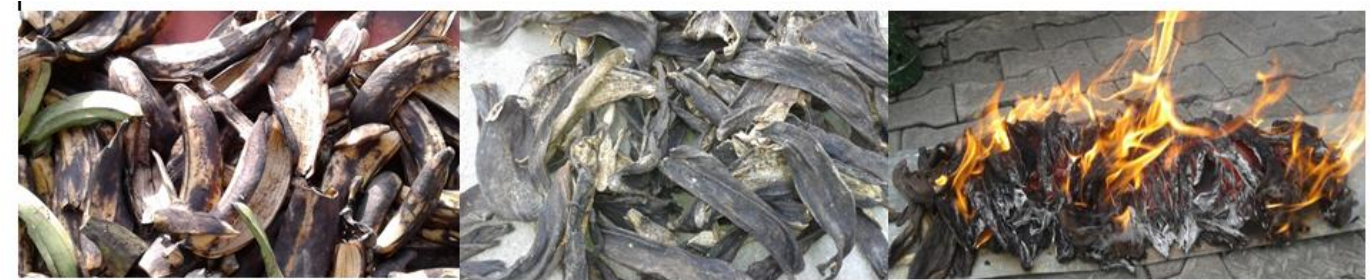

(a) Plantain Peels

(b) Drying of plantain Peels

(c) Burning of plantain Peels

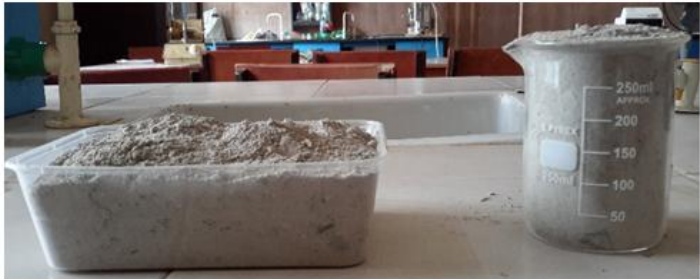

(d) Plantain Peels ashes

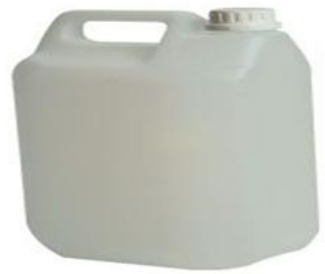

(d) Concentrated filtrate of Plantain Peels ashes

Figure4. Preparation of local sources of alkali for soap production.

\section{(C) Soap Production}

$50 \mathrm{~g}$ of Jatropha Seeds oil was heated to $70^{\circ} \mathrm{C}$ in the $400-\mathrm{mL}$ beaker and stirred with a stirring rod. 25 $\mathrm{mL}$ of concentrated filtrate of Plantain Peels ashes was gradually mixed with the heated with 
continuous stirring using an overhead mechanical stirrer. The stirring was continued until when the saponification is completed. The soap was separated from the glycerol using concentrated brine water obtained from sea water. The soap poured into a 5 litre keg.

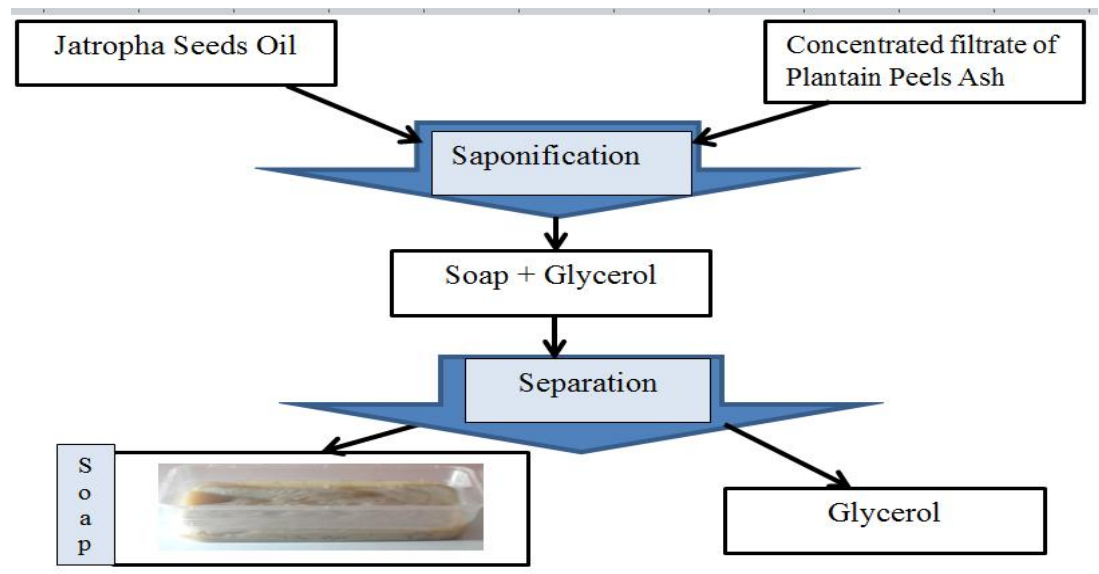

Figure5. Soap Sample Produced from Jatropha seed Oil and Plantain Peels ash

\section{(D) Soap properties Tests}

The produced solid soap was grinded into powdery form. Soap solution was prepared by adding $5 \mathrm{~g}$ of the soap with $250 \mathrm{~mL}$ of warm deionized water and swirled until the solution mixed well. The soap solution was poured into a 5 litre keg.

The properties of the soap were determined in line with methods described by Onyegbado, 2002; Warra, 2012; Rangwala and Sarasan 2014; and Sulaiman et al, 2017.

\subsection{Performance Evaluation of the Produced Soap and Conventional Surfactants in Chemical Enhanced Oil Recovery Operations}

\section{Materials}

(i) Locally produced surfactant (Soap produced from Jatropha seed oil and plantain peel ash)

(ii) Conventional Surfactants (i) Sodium Dodecyl Sulfate (SDS) (ii) Tween 80

a. Sodium dodecyl sulphate (SDS) $\left(\mathrm{CH}_{3}\left(\mathrm{CH}_{2}\right)_{11} \mathrm{SO}_{4} \mathrm{Na}^{+}\right)$with a molecular weight 288.38 is a popularly used anionic surfactant in enhanced oil recovery. It is ually a white powder with a melting point of $204-206^{\circ} \mathrm{C}$ and $\mathrm{pH}$ values of 6-9.

b. Tween 80 also called Polysorbate 80 is a nonionic surfactant and emulsifier. This synthetic compound is a viscous, water-soluble yellow liquid. It has a molar mass $1310 \mathrm{~g} / \mathrm{mol}$, a Chemical formula $\mathrm{C}_{64} \mathrm{H}_{124} \mathrm{O}_{26}$, a density of $1.06-1.09 \mathrm{~g} / \mathrm{mol}$ and oily liquid, $\mathrm{pH}$ of 8 .

(iii) Crude oil (light), $32^{\circ} \mathrm{API}$

(iv) Glass beads (soda lime glass spheres). They were used as porous media in all flooding experiments.

(v) Others materials include Brine- $\mathrm{NaCl}, \mathrm{H}_{2} \mathrm{SO}_{4}$, kerosene, deionized water.

(vi) Apparatus: Core holder (bulk volume of $112.9 \mathrm{cc}$ ), peristaltic pump, beakers, stop watch, measuring Cylinders, Fann Viscometer, Magnetic Stirrer, UPS, Weighing Balance and Oven. The Fann viscometer is used to agitate the solution for about 10 minutes to form a consistent uniform solution.

\section{(A) Sample Preparation}

(a) Brine Preparation: Brine solution was prepared by adding $2 \%$ by weight of $\mathrm{NaCl}$ into $98 \%$ pure water in a beaker. The solution was stirred for 10 minutes with a magnetic stirrer to form a uniform solution.

(b) Conventional Surfactant Preparation: Three surfactants (Sodium Dodecyl Sulfate, Tween 80) and produced soap) were used in this experiment. Three slugs of surfactant solutions were prepared 
Evaluation of Soap Produced from Agricultural Wastes and Non-Edible Oil as a Substitute for Conventional Surfactants used in Enhanced Oil Recovery

by adding $0.9 \%$ by weight of each surfactant was measured into a $99.1 \%$ brine solution $(2 \% \mathrm{NaCl})$ and stirred with a magnetic stirrer to attain a uniform surfactant solution.

\section{(c) Glass Bead Preparation}

In study, 80 microns Glass bead were used. Water wet and oil wet beads samples were prepared and used.

100\% Water Wet Glass Bead: About $1400 \mathrm{~g}$ of dry glass bead was washed and treated with 5\% of $\mathrm{H}_{2} \mathrm{SO}_{4}$ solution to etch it for the removal of any organic substances attached to it. The etched glass bead was properly rinsed to remove $\mathrm{H}_{2} \mathrm{SO}_{4}$ with sufficient water. Water was sieved out and dried in an oven for about 48 hours. The dry glass bead was labeled $100 \%$ water wet.

100\% Oil Wet Glass Bead: About 700g of the dried water wet glass bead was measured, properly soaked and mixed in kerosene. The kerosene coats the surface of the glass beads particles increasing its affinity for oil (oil wet). Kerosene was sieved out from the glass bead. Kerosene- treated glass bead was oven dried as shown below for about 72 hours to attain a completely oil wet beads.

\section{(B) Measurement of the Interfacial Tension}

The crude oil was injected into brine/surfactant solution through a capillary tube. The capillary rise method was used determined the surface tension reduction ability of the surfactants solutions. The surface tension was determined according to the well-known Young - Laplace equation:

$$
\sigma=\frac{\rho \Delta h}{\frac{2}{g}\left(\frac{1}{r_{1}}+\frac{1}{r_{2}}\right)}
$$

Where:

$\boldsymbol{\sigma}$ is interfacial tension between the two fluids (dynes $/ \mathrm{cm}$ )

$\boldsymbol{r}_{\mathbf{1}}, \boldsymbol{r}_{\mathbf{2}}$ are principal radii of curvature $(\mathrm{cm})(0.063$ and $0.3325 \mathrm{~cm}$ radius for capillary tubes were used in the experiment.

$\mathrm{g}$ is acceleration due to gravity, $\mathrm{cm} / \mathrm{sec}^{2}$

$\Delta \boldsymbol{h}=\boldsymbol{h}_{\mathbf{1}}-\boldsymbol{h}_{\mathbf{2}}=$ capillary rise, $\mathrm{cm}$

$\boldsymbol{\rho}=$ density, $\mathrm{gm} / \mathrm{cm}^{3}$

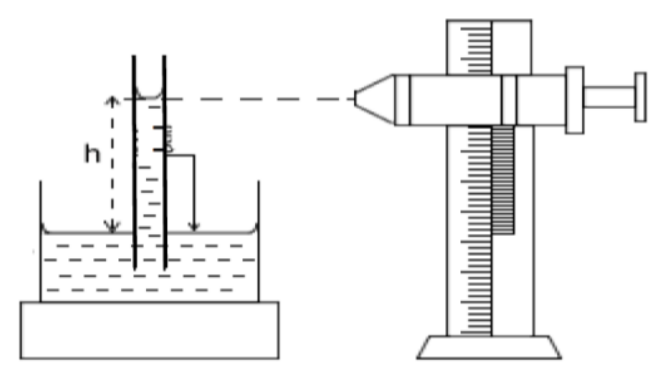

Figure6. Interfacial Tension Measurements

\section{Experimental Procedure}

Eight different experiments were performed in this work. The experimental nomenclature is shown in Table 2, while the experimental procedures and set up are shown in Figure 7 and Figure 8.

Table2. Experimental Nomenclature

\begin{tabular}{|l|l|l|l|l|}
\hline S/N & NOMENCLATURE & Wettability & $\begin{array}{l}\text { Initial Flooding } \\
\text { using }\end{array}$ & $\begin{array}{l}\text { Subsequent } \\
\text { Surfactant } \\
\text { Flooding using }\end{array}$ \\
\hline 1 & Exp. A1 & $\begin{array}{l}\text { OILWET (oil wet porous } \\
\text { media.) }\end{array}$ & Brine Solution & Produced Soap \\
\hline 2 & Exp. A2 & $\begin{array}{l}\text { AATERWET (water wet } \\
\text { porous media) }\end{array}$ & Brine Solution & Produced Soap \\
\hline 3 & Exp. B 1 & OILWET (oil wet porous & Brine Solution & SDS \\
\hline
\end{tabular}


Evaluation of Soap Produced from Agricultural Wastes and Non-Edible Oil as a Substitute for Conventional Surfactants used in Enhanced Oil Recovery

\begin{tabular}{|l|l|l|l|l|}
\hline & \multicolumn{3}{|l|}{ media.) } & \\
\hline 4 & Exp. B2 & $\begin{array}{l}\text { WATERWET (water wet } \\
\text { porous media) }\end{array}$ & Brine Solution & SDS \\
\hline 5 & Exp. C $_{1}$ & $\begin{array}{l}\text { OILWET (oil wet porous } \\
\text { media.) }\end{array}$ & Brine Solution & Tween 80 \\
\hline 6 & Exp. C $_{2}$ & $\begin{array}{l}\text { WATER WET (water wet } \\
\text { porous media) }\end{array}$ & Brine Solution & Tween 80 \\
\hline
\end{tabular}

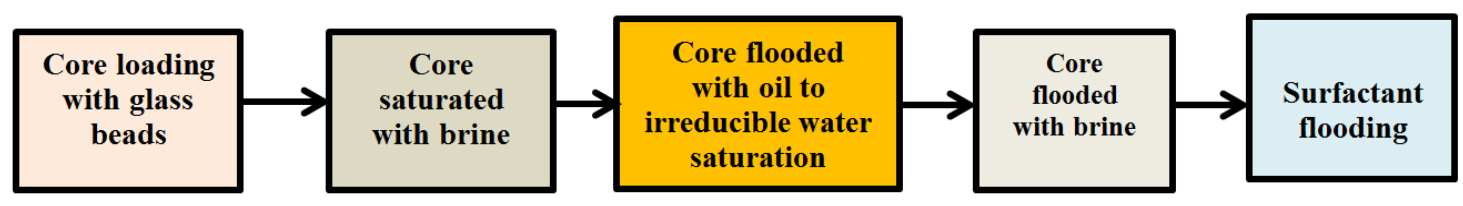

Figure7. Flow diagram of the Experiment

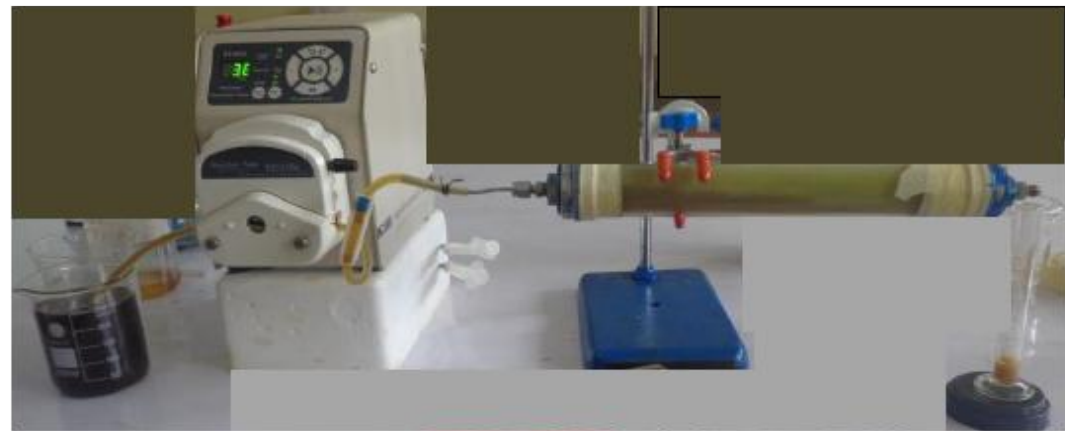

Figure8. Experimental Schematic Diagram (Adapted from Oluwaseun et al., 2016)

The procedures are outlined as follows;

i. The core holder was loaded with glass beads and weighed,

i. The core was then vacuumed for some hours at ambient temperature and later the core was $100 \%$ saturated with formation water (brine solution) and weighed again to and weighed again to calculate the pore volume.

ii. To determine the initial oil saturation and irreducible water saturation, drainage was carried out by flooding the porous media horizontally with light dead oil at a flow rate of $2.0 \mathrm{cc} / \mathrm{min}$ and the water displaced from the core holder was collected in measuring cylinder.

iii. Imbibition with $2 \%$ brine solution (water flooding) is carried out at a flow rate of $2.0 \mathrm{cc} / \mathrm{min}$. The breakthrough time is recorded. Water flooding continues until a water cut of approximately $96 \%$. This is done to determine residual oil saturation estimated based on the volume of oil collected in the measuring cylinders.

iv. The core was the flooded with the formation water at a constant speed of $2.0 \mathrm{cc} / \mathrm{min}$ until there was a breakthrough. The breakthrough time and volume oil collected in the measuring cylinders were recorded. Water flooding continues until a water cut of approximately $98 \%$. This is done to determine residual oil saturation.

v. After the water flooding, a predetermined volume (0.7 PV) of each of surfactant was flooded into the porous media at a flow rate of $2.0 \mathrm{cc} / \mathrm{min}$ and the additional oil recovery recorded.

The following calculations were made.

$$
P V=\left(\frac{\text { Wt of core holder with brine saturated glass beads }- \text { Wt of core holder with dry glass beads }}{\text { Specific Gravity of Brine }}\right)
$$

Where specific gravity of brine $=0.01197$ and Dead Volume $=2.4 \mathrm{cc}$

The Porosity is calculated as:Porosity $=\frac{\text { Pore Volume }}{\text { Bulk Volume }}$

The displacement efficiency $\boldsymbol{E}_{\boldsymbol{D}}$ was also calculated as: $E_{D}=\frac{S_{o i}-S_{o r}}{S_{o i}}=1-\frac{S_{o r}}{S_{o i}} \ldots \ldots$ 
Evaluation of Soap Produced from Agricultural Wastes and Non-Edible Oil as a Substitute for Conventional Surfactants used in Enhanced Oil Recovery

\section{RESUlTS AND DISCUSSIONS}

\subsection{Properties of Jatropha Seeds Oil and Soap Produced}

Table1. Properties of Jatropha Seeds Oil

\begin{tabular}{|l|l|}
\hline Property & Jatropha Seeds Oil \\
\hline Acid value $(\mathrm{mgKOH} / \mathrm{g})$ & 2.84 \\
\hline FFA $(\%)$ & 12.4 \\
\hline Density $\left(\mathrm{g} / \mathrm{cm}^{3}\right)$ & 0.918 \\
\hline $\mathrm{pH}$ & 8.0 \\
\hline Saponification value $(\mathbf{m g} / \mathrm{g})$ & 186 \\
\hline Iodine value $(\mathrm{mg} / \mathrm{g})$ & 102 \\
\hline S. Gravity & 0.918 \\
\hline Pour point & $8^{\circ} \mathrm{C}$ \\
\hline K. Viscosity $\left(\mathrm{cs}\right.$ or $\left.\mathrm{mm}^{2} / \mathrm{s}\right)$ & 48.2 \\
\hline Yields $(\%)$ & 62 \\
\hline
\end{tabular}

Table 1 shows some physicochemical properties of the Jatropha curcas seed. The values obtained are in favour of utilization of the Jatropha curcas seed oil for soap production (Emil et al, 2009; Salimon and Abdullah, 2008; and Akintayo, 2004).

Table2. Properties of soap produced from Jatropha seeds oil and plantain peel ash

\begin{tabular}{|l|l|}
\hline Property & Soap Produced from Jatropha Seeds Oil and Plantain Peel Ash \\
\hline Total fatty matter (TFM) & $40.80 \%$ \\
\hline Total alkali content & $0.68 \%$ \\
\hline Free Caustic Alkalinity & $0.03 \%$ \\
\hline Matter insoluble in ethanol & 10.2 \\
\hline Matter insoluble in water $(\%)$ & 2.2 \\
\hline Bulk density(w/v) & 1.20 \\
\hline Unsaponified neutral fat & 0.12 \\
\hline Leathering ability & 8 \\
\hline pH & 9.6 \\
\hline Yields $(\%)$ & 87 \\
\hline Foam height $(\mathrm{cm})$ & 5.2 \\
\hline
\end{tabular}

The parameters shown in Table 2 showed that the produced soap compared to the standard soaps sold in Nigeria (Idoko et al, 2018).

\subsection{Results of Interfacial Tension Experiments}

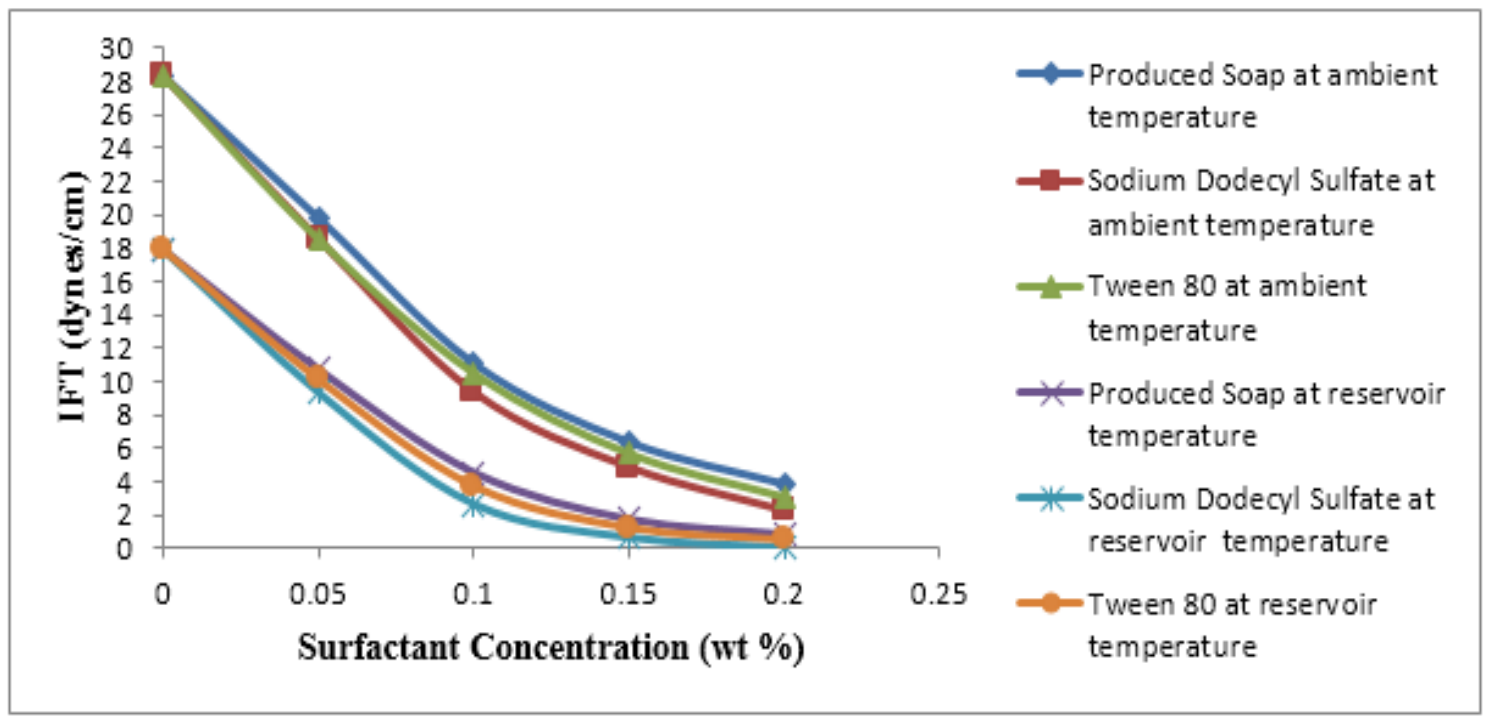

Figure9. IFT values of the produced soap and conventional surfactants with Assam crude oil

Figure 9 presents IFT values obtained at ambient and reservoir temperatures at different surfactant concentrations. The increased in concentrations reduced the interfacial tension (IFT) and the increased 
Evaluation of Soap Produced from Agricultural Wastes and Non-Edible Oil as a Substitute for Conventional Surfactants used in Enhanced Oil Recovery

in the temperature also reduced IFT. Results further showed that the produced soap reduced the interfacial tension as much as the conventional surfactants (Sodium Dodecyl Sulfate and Tween 80).

\subsection{Results of Flooding Experiments}

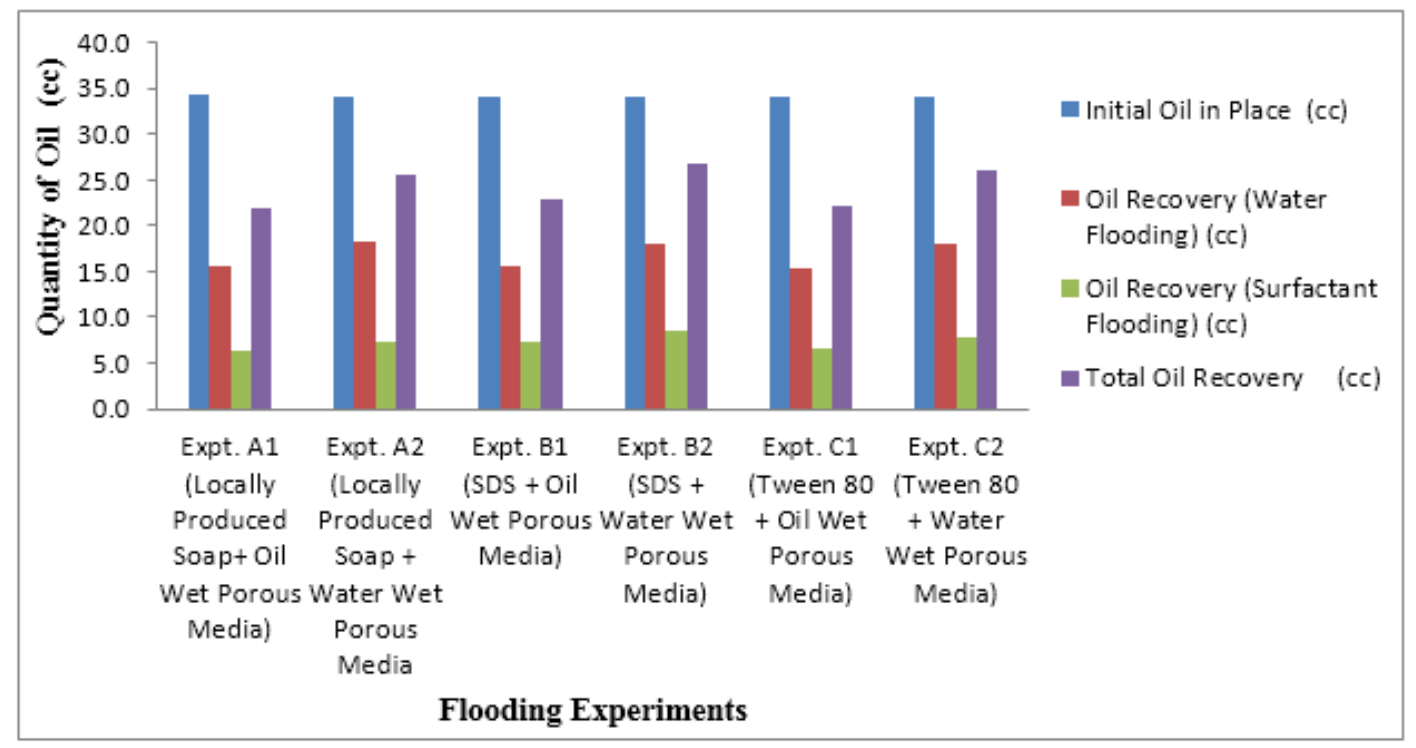

Figure10. Result of Flooding Experiments

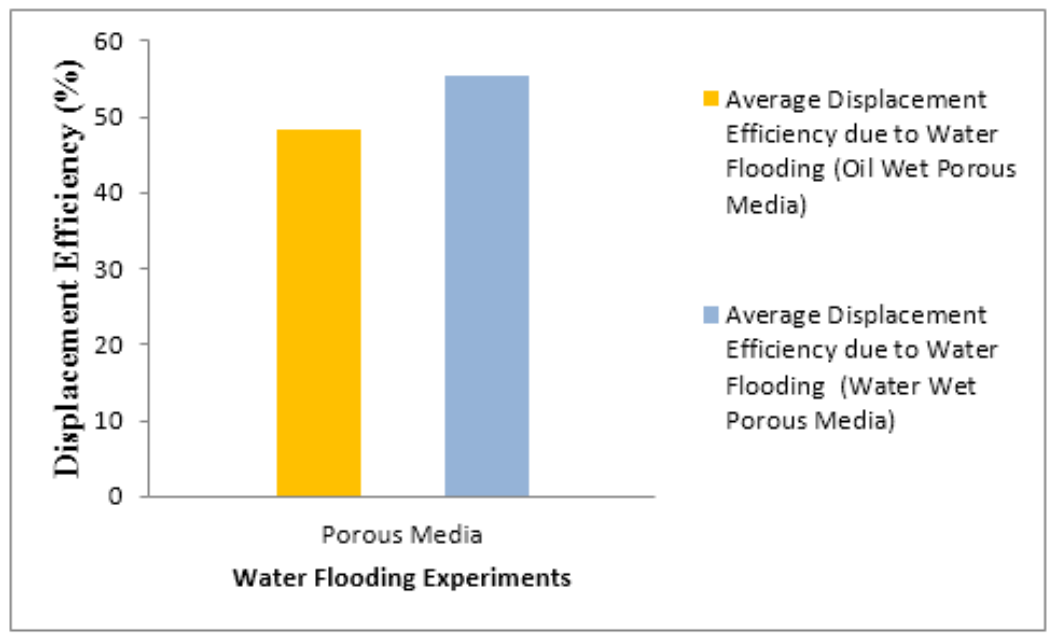

Figure11. Result of Displacement Efficiency (Water Flooding)

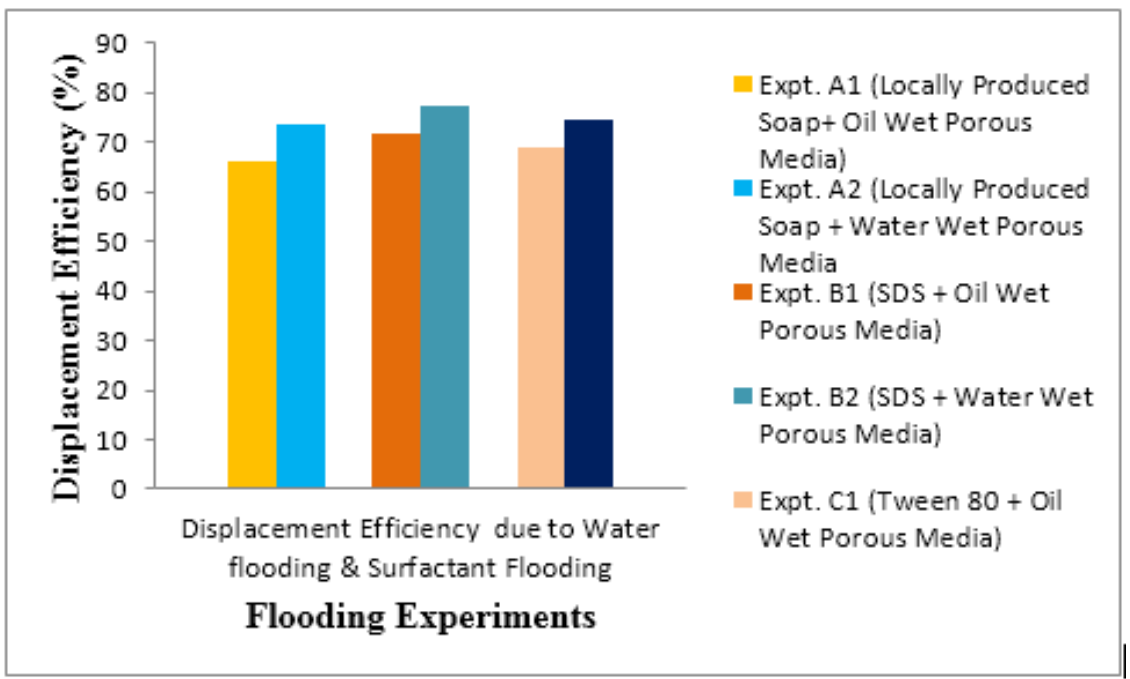

Figure12. Result of Displacement Efficiency due to water flooding and Surfactant Flooding 
Evaluation of Soap Produced from Agricultural Wastes and Non-Edible Oil as a Substitute for Conventional Surfactants used in Enhanced Oil Recovery

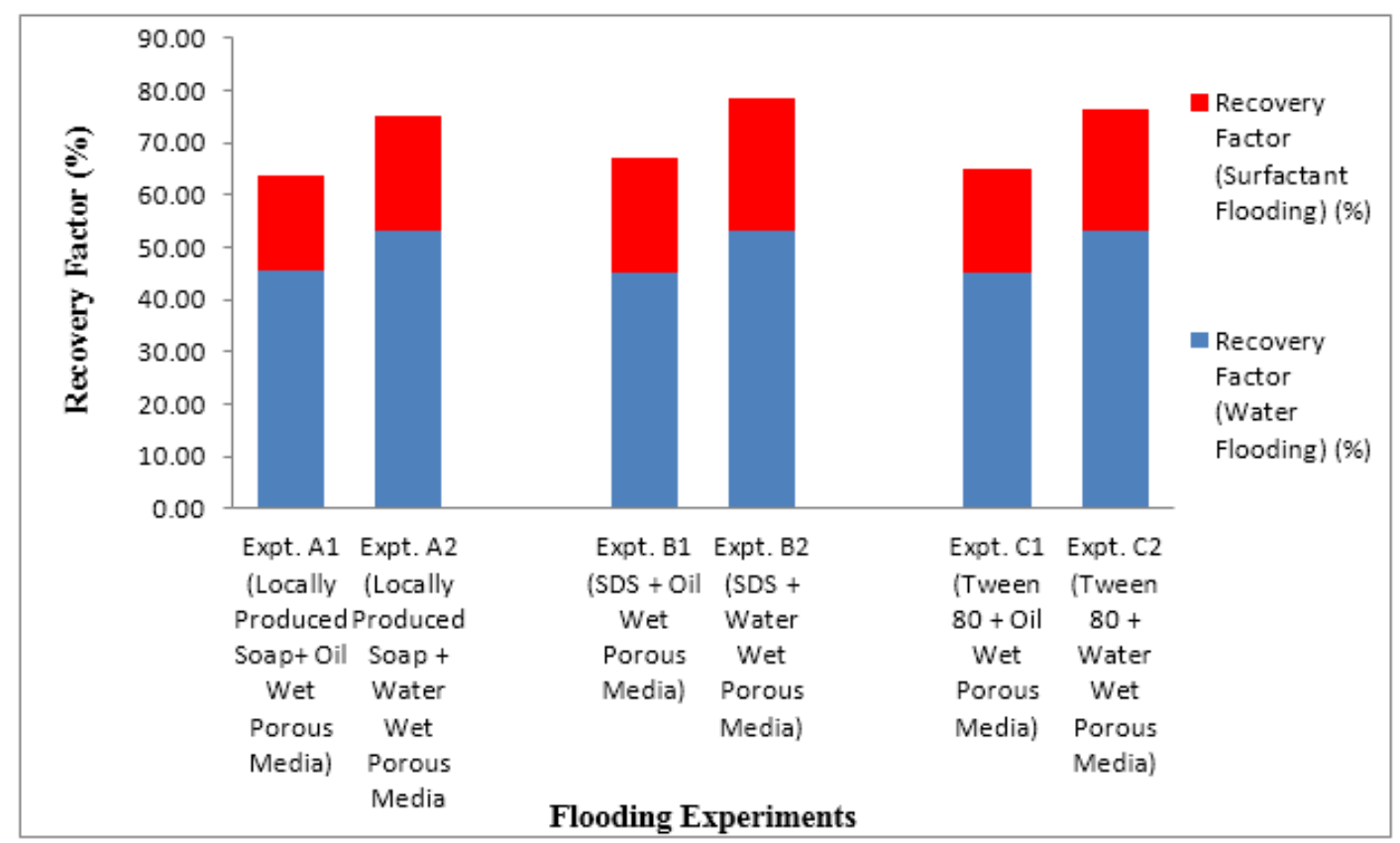

Figure13. Recovery Factors due Water Flooding and Surfactants Flooding

\section{Water Flooding}

Figure 10 and Figure 13 showed the results of the water flooding operations prior to surfactant flooding. The water flooding operations yielded an average recovery factor of $45.37 \%$ and $53.23 \%$ and an average displacement efficiency of $48.30 \%$ and $55.36 \%$ for oil wet and water wet systems respectively. These showed that water flooding effects is higher for water wet porous media than oil wet porous media. This is also in tandem with Chinedu et al., (2008) report.

\section{Surfactant Flooding}

Figure 12 and Figure 13 showed the results of the water flooding and surfactant flooding operations.

Surfactant flooding with the produced soap after water flooding in the oil wet beads yielded an additional oil recovery of $6.30 \mathrm{cc}$ (18.37\% of the Initial Oil in place). The total displacement efficiency and recovery factor due to water flooding and surfactant flooding with produced soap in oil wet beads were $66.25 \%$ and $63.85 \%$ respectively. In water wet beads pack, a further $7.40 \mathrm{cc}(21.70 \%$ of the Initial Oil in Place) was recovered with produced soap. The total displacement efficiency and recovery factor due to water flooding and surfactant flooding with produced soap in oil wet beads were $73.54 \%$ and $75.07 \%$ respectively. These results showed that surfactant flooding with the produced soap (anionic surfactant) was more effective for water wet porous media than oil wet porous media.

Flooding with Sodium Dodecyl Sulfate resulted to a further recovery of 7.4cc (about 21.64\%) for oil wet condition and 8.6cc (about 25.29\%) for the water wet condition. The displacement efficiencies resulted from water flooding and subsequent surfactant flooding with Sodium Dodecyl Sulfate for the oil wet and water wet systems were $71.68 \%$ and $77.17 \%$ respectively. The recovery factors obtained due to water flooding and the synergy of the two surfactants for the oil wet and water wet systems were $66.96 \%$ and $78.53 \%$ respectively. These results showed that surfactant flooding with the produced Sodium Dodecyl Sulfate (anionic surfactant) was more effective for water wet porous media than oil wet porous media.

Tween 80 recovered about $6.7 \mathrm{cc}$ (19.71\% of the Initial Oil in place) in oil wet and $7.9 \mathrm{cc}(23.17 \%)$ of the Initial Oil in place) in water wet packs after water flooding operations. The displacement efficiencies recorded due to water flooding and surfactant flooding with Tween 80 for the oil wet and water wet systems were $69.07 \%$ and $74.38 \%$ respectively. The recovery factors obtained due to water flooding and surfactant flooding with Tween 80 for the oil wet and water wet systems were $65.00 \%$ and $76.25 \%$ respectively. These results showed that flooding with the nonionic surfactant was more favourable to water wet systems. 
Furthermore, the flooding experiments showed that the produced soap and the conventional surfactants (Sodium Dodecyl Sulfate and Tween 80) are good enhanced oil recovery materials. The recoveries using Sodium Dodecyl Sulfate were highest followed by those of the Tween 80 and lastly the anionic locally produced soap. However, results showed that the produced soap (produced from the non-edible oil and agricultural wastes) performed comparatively well as the conventional surfactants (Sodium Dodecyl Sulfate and Tween 80). In addition, the flooding operations were more effective for water wet porous media than oil wet porous media. Changing the wettability to preferentially water-wet condition reduces the residual oil saturation (Sor) (Reza et al., 2017). This is also in tandem with ElMofty (2012) and Jagar et al., (2018) reports.

\section{CONClusion}

In this study, non-edible plant oils were extracted from Jatropha curcas seeds and the physicochemical properties measured. The values obtained are in favour of utilization of the Jatropha curcas seed oil for soap production.

Furthermore, Soap was produced from Jatropha Seeds Oil and Plantain Peels (agricultural wastes) Ash. The quality parameters measured showed that the soap is of high quality and is therefore suitable for general use.

The suitability of using the soap (surfactant) produced as substitutes for conventional surfactants used in enhanced oil recovery were also determined. Laboratory experiments (interfacial tension measurements and flooding experiments) were conducted to compare the performance of the produced soap and two conventional surfactants used in enhanced oil recovery namely Sodium Dodecyl Sulfate and Tween 80.

IFT values obtained at ambient and reservoir temperatures at different surfactant concentrations showed that the produced soap reduces the interfacial tension as much as the conventional surfactants (Sodium Dodecyl Sulfate and Tween 80). The increased in concentrations reduced the interfacial tension (IFT) and the increased in the temperature also reduced IFT.

The results of displacement efficiencies and recovery factors obtained from the flooding experiments showed that the produced soap compared favourably with the conventional surfactants. Results further showed that the recovery factors and displacement efficiencies due to water and surfactant flooding were higher for water wet systems than oil wet systems.

These interfacial tension measurements and flooding results further showed that soap produced from the non-edible oil and agricultural wastes could be used as a substitute to conventional surfactants during chemical enhanced oil surfactants flooding. Adding the right concentration of the produced soap (surfactant) to the injection water will change the wettability of the reservoir surfaces to a waterwet condition and decrease the interfacial tension (IFT) so as to increase the penetration of the injected aqueous phase into the rock matrix holding trapped oil.

\section{ACKNOWLEDGMENT}

The authors wish to thank all individuals and organizations that contributed to the success of this study.

\section{REFERENCES}

[1] Abdelmalek Atia and Kamal Mohammedi (2018): "A Review on the Application of Enhanced Oil/Gas Recovery through $\mathrm{CO}_{2}$ Sequestration".DOI: 10.5772/intechopen.79278

[2] Adeniyi A.T., Onyekonwu M.A.,Olafuyi O.A., Sonibare L.O. (2015); Development of Cost Effective Surfactants from Local Materials for Enhanced Oil Recovery" SPE- 178403.

[3] Afeez O. Gbadamosi, Radzuan Junin, Muhammad A. Manan, Augustine Agi, Adeyinka S. Yusuff (2019): "An Overview of Chemical Enhanced Oil Recovery: Recent Advances and Prospects", https://link.springer.com/article/10.1007/s40089-019-0272-8

[4] Akintayo E.T. (2004): "Characteristic and composition of Parkia biglobbossa and Jatropha curcas oils and cakes". Biosource Technology Vol. 92 pp307-310

[5] Alvarez J.O. and Schechter D.S. (2017): "Wettability Alteration and Spontaneous Imbibition in Unconventional Liquid Reservoirs by Surfactant Additives". SPE J. 20, 107-117 (2017). https://doi.org/10.2118/177057-PA 
Evaluation of Soap Produced from Agricultural Wastes and Non-Edible Oil as a Substitute for Conventional Surfactants used in Enhanced Oil Recovery

[6] Bikkina P. K., Uppaluri R., and Purkait M. K. (2013): "Evaluation of Surfactants for the Cost Effective Enhanced Oil Recovery of Assam Crude Oil Fields". Petroleum Science and Technology Volume 31, 2013 - Issue 7.

[7] Chinedu Agbalaka, Abhijit Y. Dandekar, Shirish L. Patil Santanu Khataniar and James R. Hemsath (2008): "The Effect Of Wettability On Oil Recovery - A Review". SPE-114496-MS, SPE Asia Pacific Oil and gas Conference and Exhibition, Perth, Australia.

[8] Demirbas A., Alsulami H.E. and Hassanein W.S. (2015): "Utilization of Surfactant Flooding Processes for Enhanced Oil Recovery (EOR)”. Journal- Petroleum Science and Technology Volume 33, 2015 - Issue 12.

[9] ECI (2013): "Surfactants". The Essential Chemical Industry - Online, Centre for Industry Education Collaboration (CIEC) Department of Chemistry, University of York, UK.

[10] ElMofty, Omar (2012): "Surfactant enhanced oil recovery by wettability alteration in sandstone reservoirs" (2012). https://scholarsmine.mst.edu/masters_theses/6928

[11] Emil Akbar, Zahira Yaakob, Siti Kartom Kamarudin, Manal Ismail, Jumat Salimon, Characteristic and Composition of Jatropha Curcas Oil Seed from Malaysia and its Potential as Biodiesel Feedstock, European Journal of Scientific Research. ISSN 1450-216X Vol.29 No.3 (2009), pp.396-403, (C) EuroJournals Publishing, Inc. 2009,http://www.eurojournals.com/ejsr.htm

[12] Farid Abadli, (2012); "Simulation Study of Enhanced Oil Recovery by ASP (Alkaline, Surfactant and Polymer) Flooding for Norne Field C-segment, Norwegian University of Science and Technology

[13] Funsho Afolabi (2015): “Cost-Effective Chemical Enhanced Oil Recovery". International Journal of Petroleum and Petrochemical Engineering (IJPPE) Volume 1, Issue 2, PP 1-11.

[14] Gary A. Pope (2007): “Overview of Chemical EOR”. Casper EOR workshop, Center for Petroleum and Geosystems Engineering, The University of Texas at Austin Oct. 26, 2007

[15] Hamza M. F., Sinnathambi C. M, and Merican Z. M. A. (2017): "Recent advancement of hybrid materials used in chemical enhanced oil recovery (CEOR): A review”. IOP Conf. Ser.: Mater. Sci. Eng. 206012007.

[16] Hareesh Chandra. P, Suraj Goyal, and Solomon Raju A.J (2013): "Extraction and Chemical Conversion of Jatropha seed oil into Biodiesel International Journal of Chemical, Environmental \& Biological Sciences". (IJCEBS) Volume 1, Issue 2 (2013) ISSN 2320 -4087 (Online)

[17] Hirasaki, G. J., Miller, C. A. \& Puerto, M. (2008): "Recent Advances in Surfactant EOR". SPE Annual Technical Conference and Exhibition, Denver, 21-24 (2008).

[18] Idoko O., Emmanuel S. A., Salau A. A. and Obigwa P. A. (2018): "Quality Assessment On Some Soaps Sold In Nigeria". Nigerian Journal of Technology (NIJOTECH)

[19] Iglauer S, Wu Y, Shuler P, Tang Y, Goddard WA., III (2010): "New surfactant classes for enhanced oil recovery and their tertiary oil recovery potential". Journal of Petroleum Science and Engineering.;71:2329. doi: 10.1016/j.petrol.2009.12.009.

[20] Islin Munisteri and Maxim Kotenev, (2013): "Mature Oil Fields: Preventing Decline”. THE WAY AHEAD VOL. 9 // ISSUE 3 //.

[21] Jagar A. Ali, Kamal Kolo , Abbas Khaksar Manshad, Amir H. Mohammadi (2018): "Recent advances in application of nanotechnology in chemical enhanced oil recovery: Effects of nanoparticles on wettability alteration, interfacial tension reduction, and flooding”. Egyptian Journal of Petroleum 27 (2018) 1371-1383

[22] Jerauld, G. R. and Rathmell, J.J. (1997), "Wettability and Relative Permeability of Prudhoe Bay: A Case Study in Mixed-Wet Reservoirs", SPE 28576 Reservoir Engineering, NewOrleans

[23] LTS (2011): Chemistry of Soaps and Emulsions” (C) Learning and Teaching Scotland 2011.

[24] Mohammad Zargartalebi, Nasim barati and Mojtaba Pordel Sharri (2014): "Impact of Surfactants type on Adsorption Process and Oil Recovery: Implementation of New Surfactant Produced from Zizyphus Spinal Christi- extract", Journal of Japan Petroleum Institute.

[25] Morrow, R. N. (1991): “Interfacial Phenomena in Petroleum Recovery”, Vol. 36, Pages 325-326

[26] Negin Chegenizadeh, Ali Saeedi, Xie Quan (2016): “Most Common Surfactants Employed in Chemical Enhanced Oil Recovery”. https://doi.org/10.1016/j.petlm.2016.11.007

[27] Nwidee L.N., Theophilus S.C., Barifcani A., Sarmadivaleh M. Iglauer S. (2016): "EOR Processes, Opportunities and Technological Advancements". Chemical Enhanced Oil Recovery (cEOR) - a Practical Overview. InTech, pp. 1 - 50 http://dx.doi.org/10.5772/64828

[28] Ojo T.I. and Fadairo A. S. (2017): "Effect of Jatropha Bio-Surfactant on Residual Oil during Enhanced Oil Recovery Process". International Journal of Applied Engineering Research ISSN 0973-4562 Volume 12, Number 20 (2017) pp. 10036-10042

[29] Olajire A. A., (2014): "Review Of ASP EOR (Alkaline Surfactant Polymer Enhanced Oil Recovery) Technology in The Petroleum Industry: Prospects And Challenges," Energy 77, 963 
Evaluation of Soap Produced from Agricultural Wastes and Non-Edible Oil as a Substitute for Conventional Surfactants used in Enhanced Oil Recovery

[30] Oluwaseun Ayodele Taiwo, Orivri Uzezi, Abbas Mamudu, Sean Onuoha, Ogienagbon Adijat, Olalekan Olafuyi (2016): Fractional Wettability Effects on Surfactant Flooding for Recovering Light Oil Using Teepol". SPE-184298-MS https://doi.org/10.2118/184298-MS

[31] Onyegbado, C.O., Iyagba, T. E and Offor O. J. (2002): "Solid soap production using plantain peels ashes as a source of alkali". Journal of Applied sciences and Environmental management 6; 73-77.

[32] Porte M.R, (1994): "Handbook of Surfactants", second ed. Blackie Academic \& Professional Press, London, 1994,pp 99-102.

[33] Rangwala Juzer Ali and Sarasan Geetha (2014): "Synthesis of Medicinal Soap from Non Edible (Jatropha Oil) and Study of its Quality Parameters including Antimicrobial Activity". Research Journal of Chemical Sciences

[34] Reza Qanbari Moqaddam Nouqabi, Ghasem Zargar, Mohammad Ali Takassi and Siyamak Moradi (2017): "Wettability alteration in enhanced oil recovery process using new amphoteric and cationic surfactants". Biosci. Biotech. Res. Comm. 10(4): 704-709

[35] Salager Jean-Louis, (2002): "Surfactants:Types and Uses". Universidad De Los AndesFacultad De Ingenieria Escuela De Ingenieria Quimica

[36] Saleem Qadir Tunio, Abdul Haque Tunio, Naveed Ahmed Ghirano, Ziad Mohamed El Adawy,(2011) "Comparison of Different Enhanced Oil Recovery Techniques for Better Oil Productivity". International Journal of Applied Science and Technology Vol. 1 No. 5

[37] Sandersen, Sara Bülow (2012): “Enhanced Oil Recovery with Surfactant Flooding”. Kgs. Lyngby: Technical University of Denmark (DTU).

[38] Salimon J and Abdullah R. 2008 .Physicochemical properties of Malaysian Jatropha curcas Seed oil. Sains Malaysiana. Vol. 37 No. 4 pp379-382

[39] Sulaiman Yahaya , Saidat Olanipekun Giwa, Maryam Ibrahim and Abdulwahab Giwa (2016): "Extraction of Oil from Jatropha Seed Kernels: Optimization and Characterization". International Journal of ChemTech Research

[40] Sunil, K. \& Al-Kaabi, A. (2009): “Enhanced Oil Recovery: Challenges \& Opportunities”. Journal of Petroleum Science and Engineering 64-69

[41] Susanna Laurén (2018): What are surfactants and how do they work? Copyright Biolin Scientific.

[42] Taber, J.J., Martin, F.D., and Seright, R.S.: "EOR Screening Criteria Revisited-Part 1: Introduction to Screening Criteria and Enhanced Recovery Field Projects," SPERE (August 1997) 189-198.

[43] Tarek Ahmed, (2010): "Reservoir engineering handbook, 4th ed". Gulf Professional Publishing, Elsevier

[44] Udeagbara, S.G. (2010): Effect of Temperature and Impurities on Surface Tension of Crude Oil, reprint), Universal Publishers, USA, 2010.

[45] Warra, A. A. (2012): "Cosmetic potentials of physic nut (Jatropha curcas Linn.) Seed oil: A Review". American Journal of Scientific and Industrial Research

[46] William A. Goddard, Yangchuan Tang, Patrick Shuler, Mario Blanco and Yongfu Wu (2007): “Cost Effective Surfactant Formulations for Improved Oil Recovery in Carbonate Reservoirs", DOE Project: DE-FC26-04NT15521

Citation: Azuokwu Augustine Azubike, et.al, (2020). "Evaluation of Soap Produced from Agricultural Wastes and Non-Edible Oil as a Substitute for Conventional Surfactants used in Enhanced Oil Recovery", International Journal of Petroleum and Petrochemical Engineering (IJPPE), 6(1), pp.1-13, DOI: http://dx.doi.org/10.20431/2454-7980.0601001

Copyright: (C) 2020 Authors. This is an open-access article distributed under the terms of the Creative Commons Attribution License, which permits unrestricted use, distribution, and reproduction in any medium, provided the original author and source are credited 